\title{
MICROSTRUCTURAL EVOLUTION OF NICKEL-BASE SUPERALLOY FORGINGS DURING INGOT-TO-BILLET CONVERSION: PROCESS MODELLING AND VALIDATION
}

\author{
C.A. Dandre, C.A. Walsh, R.W. Evans*, R.C. Reed and S.M. Roberts
} Rolls-Royce University Technology Centre, Department of Materials Science and Metallurgy, University of Cambridge, Pembroke Street,
Cambridge, CB2 3QZ, UK. *IRC for Computer Aided Materials Engineering, Department of Materials Engineering, University of Wales Swansea, Singleton Park,
Swansea, SA2 8PP, UK.

\begin{abstract}
A computer-based process modelling capability has been developed to simulate the evolution of microstructure during ingot-to-billet conversion of nickel-base superalloys. A unique fcature of the model is the incorporation of rules describing the dynamic and static recrystallisation phenomena that govern microstructural development. Computational investigations consider the influence of process control parameters such as die velocity and displacement to obtain an optimal microstructure. Furthermore, a comparison is made of the cffective strain profiles obtained by squeezing flat versus rounded sections of the workpiece.
\end{abstract}

\section{Introduction}

This paper is concerned with the development and application of a computer-based process model for the simulation of microstructural evolution [1-4], which occurs during the thermomechanical working of superalloys, e.g. Inconel ${ }^{\otimes} 718^{1}$ and Waspaloy, for the purposes of ingot-to-billet conversion. It would appear that only very little attention $[5,6,7]$ has been paid to the analysis of the cogging process, despite its significance to the materials suppliers and its relevance to the manufacturers of gas turbines. Our initial studies were on Inconel ${ }^{\$} 718$ but have latterly been extended to encompass Waspaloy. Generically the strain and strain-rate distributions due to cog forging are considered similar for these alloys, although the relationship between the strain path and the microstructural evolution may differ slightly.

During the cogging process, the optimum amount of deformation must be imposed at the correct temperature within the right timescale. A description of all the relevant phenomena has been attempted. The complex relationship between the processing parameters, the flow field and the microstructure is time dependent and strongly temperature dependent. The development of microstructure during ingot breakdown is governed by the various recrystallisation phenomena occurring. Under dynamic loading conditions, dynamic recrystallisation may occur. When the dics are removed, a significant period of dwell can be expected before the same volume of material is worked again. During this period static recovery, static (meta-dynamic) recrystallisation and grain growth may occur; it has been found that it is these phenomena which control the development of microstructure.

\footnotetext{
${ }^{1}$ Inconel a trademark of Special Metals Corporation
}

The details of the model are given with particular emphasis placed on the description of microstructural evolution. A comprehensive testing programme using a purpose built compression testing machine has been carried out to acquire the materials data required for the model. The analysis of the flow curves is described. The microstructural model has been implemented within the three-dimensional visco-plastic Forge $3^{\mathrm{rw} / 2}$ finite element software. In order to validate the methodology developed, interrupted cogging trials have been performed. The evolution of microstructure is explained in terms of the cogging model and a more optimal process procedure suggested.

\section{Nickel-base superalloys for disc applications}

This paper considers the nickel-base superalloys Inconel ${ }^{\Phi} 718$ and Waspaloy. Typical compositions of the two alloys considered are given in Table 1 [8]. These materials are used extensively for the production of high integrity gas turbine discs due to their excellent high temperature mechanical properties. These properties may be further enhanced by careful control and consideration of the processing route employed for disc manufacture. Ingot production involves a primary melting process e.g. vacuum induction melting (VIM) followed by a remelt procedure e.g. vacuum arc remelting (VAR) and/or electro slag refining (ESR). Following a homogenisation treatment to minimise the effects of macrosegregation, the ingot is then converted into a wrought product in billet form in order to breakdown the coarse, nonuniform as-cast grain structure. The resulting refined wrought structure is then suitable for supply to the forgemasters for near net shape disc forging. The final operations of ageing heat treatments and machining are not considered to affect the grain evolution.

The control of microstructure during the cogging process and during subsequent disc forging is essentially a compromise; higher temperatures enable larger amounts of strain to be imparted in a given step hence minimizing cost, at the same time however, higher temperatures have a detrimental effect on grain growth.

Table 1. Nominal alloy compositions (wt \%) [8]

\begin{tabular}{l|llllllll}
\hline Alloy & $\mathrm{Ni}$ & $\mathrm{Cr}$ & $\mathrm{Co}$ & $\mathrm{Mo}$ & $\mathrm{Fe}$ & $\mathrm{Al}$ & $\mathrm{Ti}$ & $\mathrm{Nb}$ \\
\hline Waspaloy & 58 & 19.5 & 13.5 & 4.3 & - & 1.3 & 3.0 & - \\
Inconel $^{\circledR} 718$ & 52.5 & 19.0 & - & 3.0 & 18.5 & 0.5 & 0.9 & 5.1 \\
\hline
\end{tabular}

${ }^{2}$ Forge 3 a trademark of Transvalor 
The principal difference between the alloys is the substitution of iron and niobium (Inconel ${ }^{6} 718$ ) for cobalt (Waspaloy). For Inconel ${ }^{\circ} 718$, this leads to the formation of phases other than the ordered $\mathrm{Ll}_{2}$ gamma prime $\left(\gamma^{\prime}\right)$ phase [9]. In particular the $\mathrm{Ni}_{3} \mathrm{Nb}$ delta $(\delta)$ phase is often formed, although at lower temperatures the meta-stable gamma double prime ( $\gamma$ ') phase arises. As is well known, the 718 alloy is the workhorse of the nickel-base superalloys and accounts for $40-50 \%$ of all superalloys produced $[9,10]$. The high temperature capacity of the cobalt rich Waspaloy is dominated by the volume fraction of gamma prime $\left(\gamma^{\prime}\right)$ formed, typically around $25 \%$. In considering the forging sequences for these alloys it is necessary to consider the influence of the two major solvus temperatures. For Waspaloy, the $\gamma^{\prime}$ solvus has been reported to be $1030^{\circ} \mathrm{C}$ [11]. For Inconel ${ }^{\oplus} 718$, the $\delta$ solvus is $1000^{\circ} \mathrm{C} \pm 20^{\circ} \mathrm{C}$, dependent upon the niobium content $(4.7-5.5$ $\mathrm{wt} \%)$ [12].

\section{The Cogging Process}

The cogging process is an open-die thermomechanical forging operation that converts the as-cast ingot into a wrought product in billet form. The purpose of ingot-to-billet conversion is to break down the coarse as-cast, as-homogenised ingot microstructure to achieve a much refined and consistent microstructure. The opendie cogging process is a traditional approach to ingot breakdown, deriving from the introduction of the steam press in the 1840's.

The process involves passing the workpiece repeatedly through an open-die press to reduce the ingot diameter. The exact manner in which the workpiece is cycled through the press is varies from producer to producer, however the operation typically involves rotating the workpiece (e.g. through $45^{\circ}$ or $90^{\circ}$ ) at the end of each pass in order to maintain a symmetrical octagonal or square crosssection. By working the sides down the length of the ingot via a series of narrow tool width ('bites'), strain is imposed within the deforming material by reducing the diameter at discrete time steps. The amount and rate of applied strain, together with the temperature, are key variables which influence the flow stress of the material.

However, due to the relatively large section sizes of the ingot (e.g. $380-520 \mathrm{~mm}$ diameters), full strain penetration may not be achievable. Instead, the cogging process comprises a number of stages, or heats, of limited deformation; after this, the workpiece is returned to the furnace for re-heat. As many as seven heats might be required to $\operatorname{cog}$ a 3 tonne ingot whilst maintaining uniformity of temperature and ease of forging. Figures 1(a-d) show the starting ingot size, two consecutive intermediate stages of the process, and the final as-cogged (rounded) billet section for a Waspaloy cogging.

The furnace temperatures are set in accordance with the stage of processing. Initial ingot forging is generally performed at a temperatures well above the carbide, $\delta$ and $\gamma^{\prime}$ solvii (Inconel ${ }^{\circledR} 718$ $1120^{\circ} \mathrm{C}$, Waspaloy $1170^{\circ} \mathrm{C}$ ). Conversely final forging is performed close to the relevant solvii. For Inconel ${ }^{\otimes} 718$, final forging is performed at, or just above, the $\delta$ solvus at around $1010^{\circ} \mathrm{C}$. As a consequence, $\delta$-phase particles form which restrict subsequent grain growth by impingement of grain boundaries and which also act as nucleation sites for recrystallisation events. For Waspaloy, the final forging is performed around the $\gamma^{\prime}$ solvus, at approximately $1040^{\circ} \mathrm{C}$.

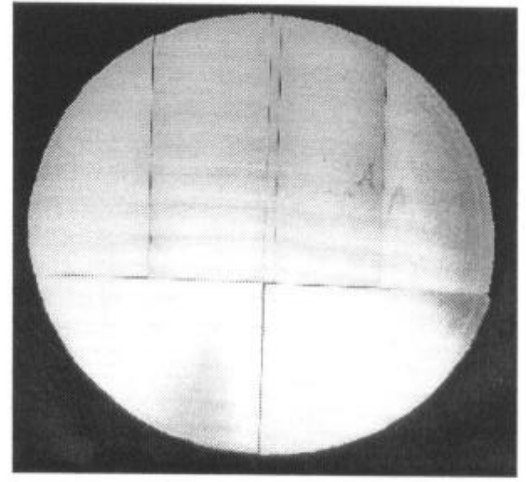

Figure 1(a). As-cast, as-homogenised section of Waspaloy.

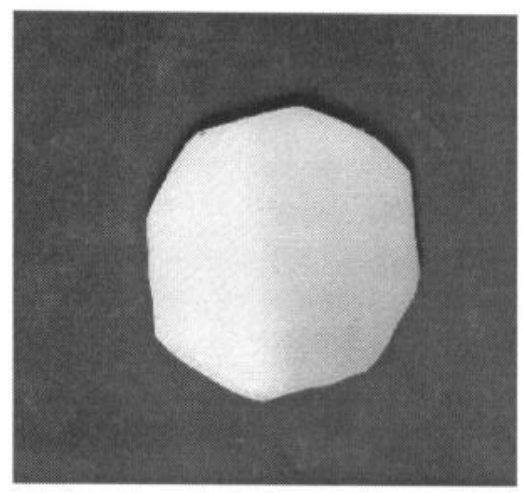

Figure 1(b). Intermediate stage 3 of Waspaloy.

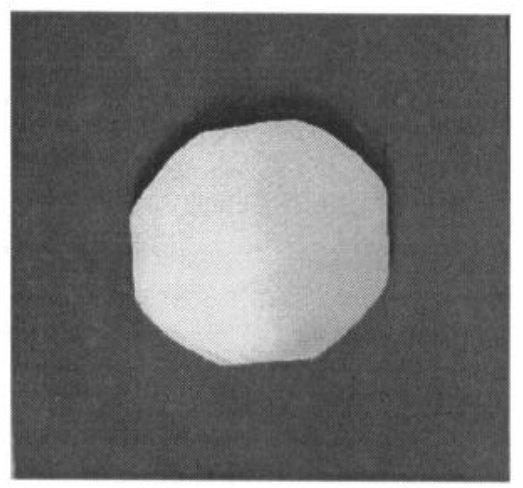

Figure 1(c). Intermediate stage 4 section of Waspaloy.

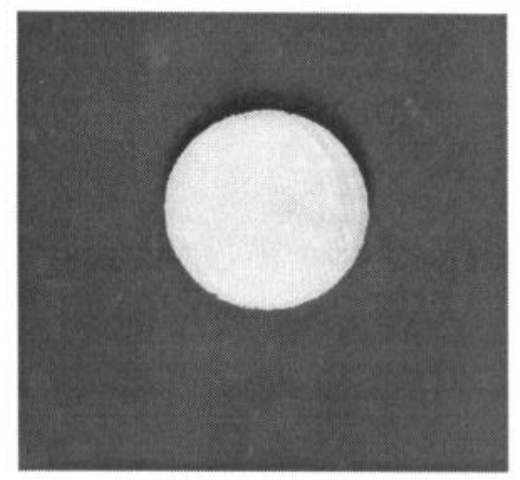

Figure 1(d). Final as-cogged section of Waspaloy. 


\section{The Process Model}

As an example of the application of the model we consider a three-dimensional simulation of a Special Metals Wiggin Ltd. production schedule, which involves the reduction of a 2 tonne, $380 \mathrm{~mm}$ diameter as-cast as-homogenised ingot of Inconel ${ }^{\$} 718$. Both radiative heat loss during transfer from furnace-to-press and heat conduction due to die contact have been modelled. Thermal predictions associated with radiative heat losses have been validated through pyrometric measurements of the ingot skin temperature, which cools from 1120 to $1060^{\circ} \mathrm{C}$ during furnace-topress transfer. A shear friction factor of 0.38 is used to represent the interaction between die and ingot surfaces. The die speed has been set at a constant $40 \mathrm{~mm} / \mathrm{s}$.

The constitutive model follows the methodology of Evans $[1,2]$ and uses the Sellars-Teggart [13] inverse sinh relationship given in Equation 1:

$$
\sigma=\frac{1}{\alpha} \sinh ^{-1}\left[\left\{\frac{\varepsilon}{\mathrm{A}} \exp \left(\frac{\mathrm{Q}_{\mathrm{dr}}}{\mathrm{RT}}\right)\right\}^{\frac{1}{\alpha^{\prime}}}\right]
$$

This relationship may be used to define the yield stress $\left(\sigma_{1}\right)$, maximum stress $\left(\sigma_{2}\right)$ and steady-state stress $\left(\sigma_{3}\right)$ in terms of both temperature and strain rate. These points are illustrated on the experimental stress-strain curves in Figure 2.

A further equation relates the strain $\left(\varepsilon_{2}\right)$ at the maximum stress to the strain rate and temperature and is given in Equation 2:

$$
\varepsilon_{2}=B \dot{\varepsilon}^{m} \exp \left(\frac{Q_{\varepsilon}}{R T}\right)
$$

Between $\sigma_{1}$ and $\sigma_{2}$ the work hardening portion of the flow curve is described by a second order polynomial. The softening portion of the curve is described by a linear fit and steady state conditions are assumed to ensue at 0.4 strain.

Unique sets of constants $\left(\alpha, A, n^{\prime}, Q_{d \epsilon}, B, \mathrm{~m}\right.$ and $\left.Q_{\varepsilon}\right)$ are required for each of the points corresponding to $\sigma_{1}, \sigma_{2}, \sigma_{3}$ and $\varepsilon_{2}$ [14]. A comprehensive compression testing programme was devised which considered a range of temperatures $\left(950-1150^{\circ} \mathrm{C}\right)$ and strain-rates $\left(0.001-10 s^{-1}\right)$ to derive these constants. Specimens were machined into cylinders having $6 \mathrm{~mm}$ diameter and $8 \mathrm{~mm}$ height. The geometry of the specimens was selected to minimise the barrelling effects associated with friction. The specimen/platen surfaces were glass lubricated during testing. All tests were conducted under isothermal conditions and taken to a true strain of approximately 0.5 which resembles sufficiently closely the amount of deformation applied during the cogging operation. Compressed specimens were immediately water quenched upon removal from the testing furnace. The specimens were obtained from wrought product and were determined to have starting grain sizes of ASTM 5/6. Stress-strain curves for Inconel ${ }^{\star} 718$ at $1080^{\circ} \mathrm{C}$ are shown in Figure 2.

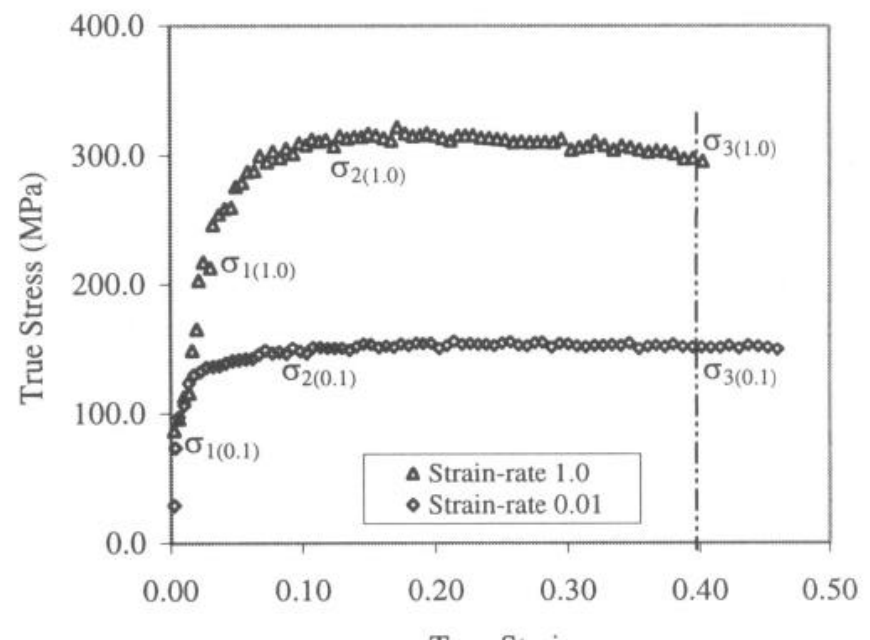

Figure 2. Typical stress-strain curves for Inconel ${ }^{\circledR} 718$.

The tool developed has been used to give an insight into the way in which microstructure evolves through careful study of the first and second passes.

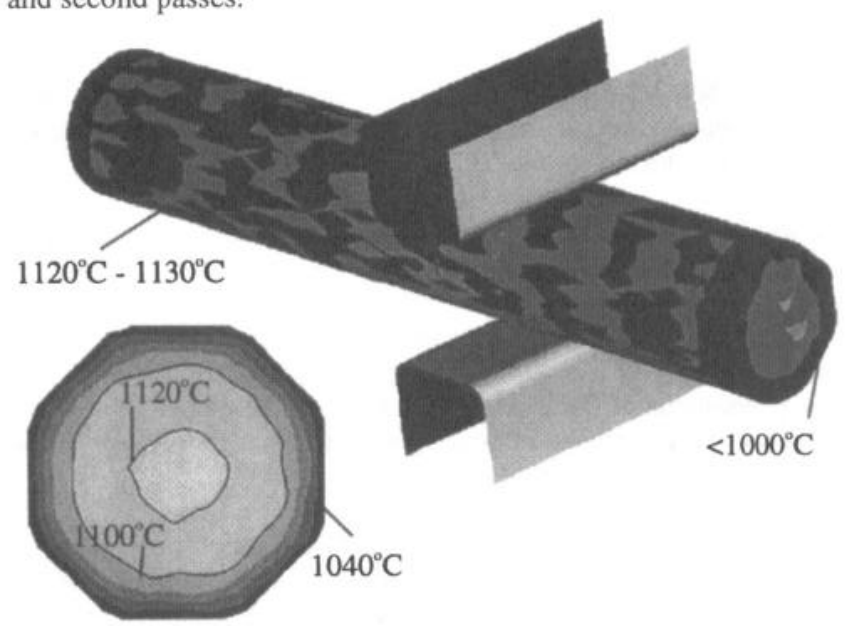

Figure 3. Numerical prediction of cogged billet temperatures.

Figure 3 shows both a three dimensional representation of the workpiece temperatures and a section at the mid-length. Adiabatic heating can be seen to have raised the centre section temperature above the initial $1120^{\circ} \mathrm{C}$, whilst radiative and conductive losses have cooled the ingot surface. Towards the end of the ingot, the surface cooling is observed to be even more dramatic due to the extra surface area there. The value for the end section of between $1020^{\circ} \mathrm{C}$ at the centre, and $990^{\circ} \mathrm{C}$ at the corners, is in excellent agreement with the measured temperature of $1008^{\circ} \mathrm{C}$. This has a significant effect on the variation of microstructure both through the cross section of the billet and along the billet length. 


\section{The Microstructural Model}

A microstructural evolution model, which has been described elsewhere [1,2,4,14] and previously assessed [15], has been incorporated into the FORGE $3^{\text {sw }}$ finite element software package. Microstructural development is described using a number of purpose-built routines, which have been incorporated into the code. The dominant mechanisms for microstructural development during ingot breakdown are taken to be static recrystallisation and grain growth, which occur during periods of dwell between successive bites [16,17]. Previous observations assume that dynamic recrystallisation has a negligible influence on the evolving structure $[18,19]$, which has been demonstrated to occur under specific conditions of temperature and strain-rate [20].

From an investigation of the flow curves and empirical measurements of microstructure three regimes have been identified; dynamic recrystallisation (DRX), dynamic recovery (DRV), and static (meta-dynamic) recrystallisation (SRX) with subsequent grain growth $[1,2,14]$.

The softening behaviour exhibited by the material under applied load is indicative of DRX and/or deformational (adiabatic) heating. Upon closer examination of the Inconel ${ }^{\circledR} 718$ flow curves, there is considerable evidence to suggest that softening by DRX occurs only above both (i) a critical strain-rate of $0.1 \mathrm{~s}^{-1}$ and (ii) a critical level of strain accumulation $\left(\varepsilon_{\mathrm{DRX}}=\varepsilon_{2}\right)$. At the onset of DRX, strain-free grains nucleate and appear with a distinct size governed solely by the instantaneous temperature and strain-rate. The nucleation rate is similarly govemed by the instantaneous temperature and strain-rate.

At and below strain-rates of $0.1 \mathrm{~s}^{-1}$ a plateau appears in the flow curve, with no further hardening nor any softening, which is indicative of dynamic recovery (DRV). Further straining results in the local generation of dislocations which are effectively annihilated to give a reduction in the local dislocation length [21]. The phenomena of DRV is not simulated in the model since static recovery, recrystallisation and grain growth are considered to overrule the effects of DRV.

If, under applied load, there has been insufficient work to drive dynamic deformation mechanisms, then the level of plastic strain accumulation may still be sufficient to drive SRX. Here, it is considered that SRX encompasses the processes of (a) static recovery which is followed by (b) subsequent recrystallization of strain-free grains $(\sim 1 \mu \mathrm{m})$, which (c) grow at a rate dependent on the temperature. If the strain reaches a critical level $\left(\varepsilon_{\mathrm{SRX}}=0.8 \varepsilon_{2}\right)$, then SRX is assumed to occur upon removal of the applied load. If the level of strain accumulation is insufficient, then the strain energy is stored for future events. The model considers a static time variable which tracks dwell time between stages of SRX and which is used to determine the extent of static grain growth. The Avrami relationship is employed to describe the volume fraction of statically recrystallized material.

The recrystallisation logic applied is summarized in Figure 4. It is the belief of the investigators that, for a given temperature, there is a change in deformation mechanisms with decreasing strainrates. At 'extreme' strain-rates (10-20s $\left.\mathrm{s}^{-1}\right)$, flow softening can be expected and is attributable to adiabatic heating. Dynamic recrystallisation may also play a significant role, whereby DRX grain growth may occur in the absence of $\delta$-phase.
At 'high' strain-rates (1-10s $)$, flow softening may still occur, however this is almost exclusively due to dynamic recrystallisation (DRX).

At 'intermediate' strain-rates $\left(0.01-0.1 \mathrm{~s}^{-1}\right), \mathrm{DRX}$ is less apparent and DRV becomes the dominant deformation mechanism, which is reflected by the plateau in the flow curve beyond peak stress.

At 'low' strain-rates $\left(<0.01 \mathrm{~s}^{-1}\right)$, a portion of DRV is considered to take place followed by softening which is attributable to grain boundary rotation and/or sliding. The frictional effects associated with grain boundary sliding are considered to break up material which experiences the greatest frictional forces. These regions accumulate sufficient strain to cause DRX. This is believed to result in the appearance of a necklace structure. This is illustrated in the microstructure observed in the Waspaloy ingot material after cogging (Figure 6). However, between strain-rates of 0.1 and $1 \mathrm{~s}^{-1}$ there is a distinct change in the deformation mechanism which is supported by the transition in flow curves from a plateau to a softening mechanism. Generally, as strain-rate is increased from 0.1 to $1 \mathrm{~s}^{-\tau}$, the deformation mechanism shifts from DRV to DRX. Consequently, a critical strain-rate of $0.1 \mathrm{~s}^{-1}$ is incorporated into the microstructural model to simulate the restrictions of the DRX mechanism.

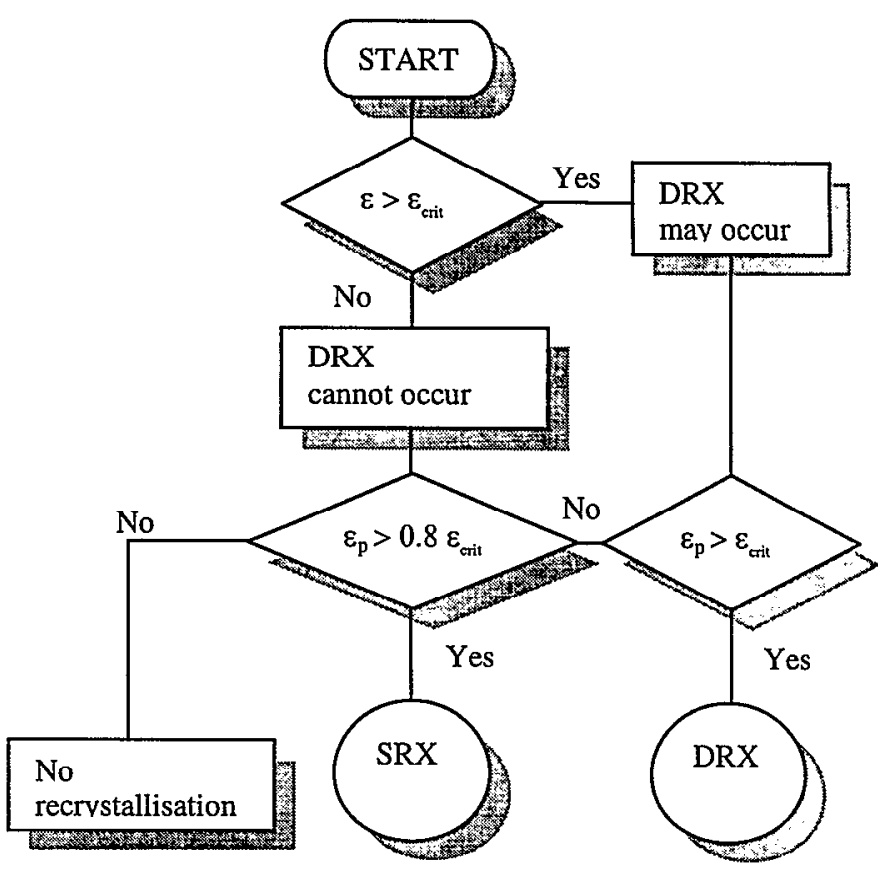

Figure 4. Recrystallisation logic.

Figure 2 provides good evidence that, for Inconel ${ }^{\oplus} 718$, flow softening occurs only above a critical strain-rate of $0.1 \mathrm{~s}^{-1}$. Below this level, DRV events may occur. However, upon removal of the load, SRX will dominate microstructural evolution during dwell periods between blows. It is imperative that this dwell period is minimised in order to achieve a finer recrystallised microstructure. 
Figure 5 shows a three-dimensional image of the computational process model for the Inconel®718 material: the predictions indicate the level of static grain growth within the workpiece at the end of the fourth pass. For a mid-length section, the model predicts ASTM 3/4 at the centre and mid-radius locations. The microstructure is much finer at the edge, ASTM 5/6. Such refinement is expected due to the lower temperature at the edges of the ingot compared to the adiabatically heated centre (Figure 3). A finer structure is predicted for the end of the workpiece since this material has just recrystallised. After some time, however, a grain size slightly finer than that of the bulk might be expected to due to the lower temperatures at the extremities of the workpiece. As discussed earlier, the lower temperatures offer less driving force for grain growth and, for temperatures below the $\delta$ solvus, grain growth becomes impinged. Table 2 illustrates the measured and predicted variation in microstructure [4] for the Inconel ${ }^{\circ} 718$ material and clearly shows these phenomena.

$\underline{\text { Table 2. Microstructural results: observations versus predictions }}$ (Inconel ${ }^{8} 718$ ).

\begin{tabular}{|c|c|c|c|c|c|c|}
\hline \multirow{2}{*}{ Location } & \multicolumn{3}{|c|}{$\begin{array}{c}\text { Mean RXD Grain Size } \\
\text { (ASTM) }\end{array}$} & \multicolumn{3}{|c|}{$\begin{array}{c}\text { Volume Recrystallised } \\
(\%)\end{array}$} \\
\cline { 2 - 4 } & \multirow{2}{*}{ Observed } & \multicolumn{2}{|c|}{ Predicted } & \multirow{2}{*}{ Observed } & \multicolumn{2}{c|}{ Predicted } \\
\cline { 3 - 4 } & & $\begin{array}{c}\text { Mid- } \\
\text { length }\end{array}$ & End & & $\begin{array}{c}\text { Mid- } \\
\text { length }\end{array}$ & End \\
\hline Centre & $3 / 4$ & $3 / 4$ & $6 / 7$ & 86 & 100 & 84 \\
\hline Mid-radius & $3 / 4$ & $3 / 4$ & $5 / 6$ & 87 & 100 & 89 \\
\hline Edge & 6 & $5 / 6$ & $6-8$ & 94 & 100 & 97 \\
\hline
\end{tabular}

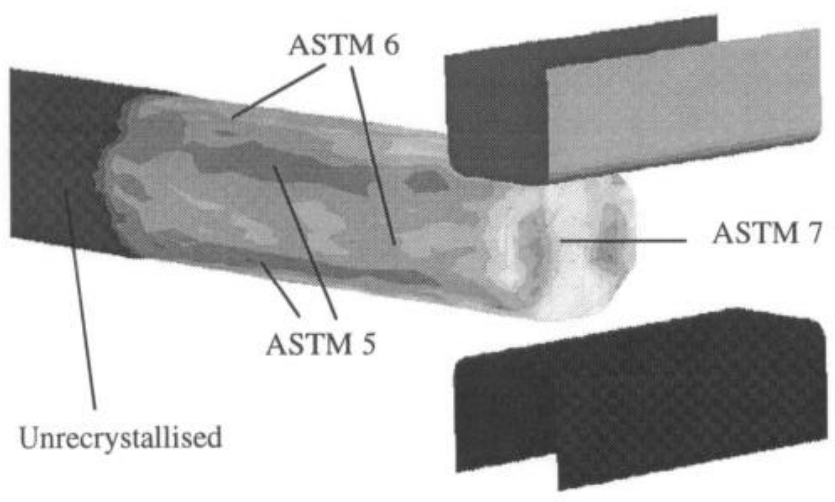

\section{Analysis of as-cogged billet section}

Two forms of analysis were performed on cogged material. For the final stage of the as-cogged Inconel ${ }^{\otimes} 718$ both chemical and microstructural analysis was performed. The Inconel ${ }^{*} 718$ microstructural results are recorded in Table 2 above. For the Waspaloy material only microstructural analysis has been performed so far, however this covers a number of cogging stages.

The chemical analysis in Inconel ${ }^{\oplus} 718$, as can be seen in Table 3 below, indicated no significant macrosegregation across the radius of the ingot.

In Waspaloy, samples from the centre, mid-radius and periphery of the billet were characterized for stages $3,4,5,6$ and 7 . Stages 3,4 and 7 are shown in Figure 1, and a macroetched example of stage 5 is shown in Figure 8. Three images from different areas of each sample were analysed semi-automatically using a macroprogram in conjunction with the Kontron Elektronik Imaging System KS300 v2.00 image analysis software package. The linear intercept technique was used as the basis for this analysis. A macro-program produced a series of lines in two orthogonal directions on each micrograph. The positions of the intercepts of these lines with the grain boundaries were then marked off manually using a mouse to position the cursor appropriately. The computer calculated and stored the intercept lengths in a database. Twin boundaries were not included in this analysis. The sum of the intercept lengths in each orthogonal direction was kept approximately equal. The total number of intercepts measured for each sample was typically between 500 and 1000 . A mean ASTM grain size for each sample was obtained from the mean intercept length, $l(\mathrm{~mm})$ using the ASTM Standards [22] formula

$$
\mathrm{G}=3.2877-6.643856 \log 10(l)
$$

The distribution of the intercept lengths for each sample as a function of fractional intercept length is shown as raw data. For each intercept measured this was calculated as

$$
\text { LFR }=\frac{100 \times \text { intercept length }}{\text { sum of all intercept lengths measured }}
$$

This length fraction was then converted to the more familiar ASTM distribution of grain size as a fraction of intercept length.

The micrographs in Figure 6 are taken from the centre, mid-radius and edge locations of the as-cogged, stage 7 material. Microstructural analysis considered the distribution of intercept lengths for the samples associated with these regions.

Figure 5. Prediction of SRX grain size as a function of position along the ingot length (Inconel ${ }^{\circ} 718$ )

Table 3. Results of chemical analysis for as-cogged section of Inconel ${ }^{\circ} 718$ (Weight \% except ppm - parts per million).

\begin{tabular}{ccccccccccccccccc}
\hline Location & $\mathrm{C}$ & $\mathrm{Si}$ & $\mathrm{Mn}$ & $\mathrm{P}$ & $\mathrm{S}$ & $\mathrm{Al}$ & $\mathrm{Co}$ & $\mathrm{Cr}$ & $\mathrm{Cu}$ & $\mathrm{Fe}$ & $\mathrm{Mo}$ & $\mathrm{Nb}$ & $\mathrm{Ni}$ & $\mathrm{Ta}$ & $\mathrm{Ti}$ & $\mathrm{B}$ \\
\hline Centre & 0.030 & 0.15 & 0.20 & 0.008 & $<0.001$ & 0.48 & 0.18 & 19.3 & 0.07 & 17.0 & 2.97 & 5.17 & 53.2 & $<0.01$ & 0.93 & $38 \mathrm{ppm}$ \\
Mid-radius & 0.025 & 0.14 & 0.20 & 0.008 & $<0.001$ & 0.48 & 0.13 & 19.4 & 0.08 & 17.0 & 2.96 & 5.18 & 53.1 & $<0.01$ & 0.93 & $37 \mathrm{ppm}$ \\
Edge & 0.028 & 0.14 & 0.20 & 0.008 & $<0.001$ & 0.48 & 0.14 & 19.4 & 0.08 & 17.0 & 2.97 & 5.19 & 53.0 & $<0.01$ & 0.94 & $39 \mathrm{ppm}$ \\
\hline
\end{tabular}




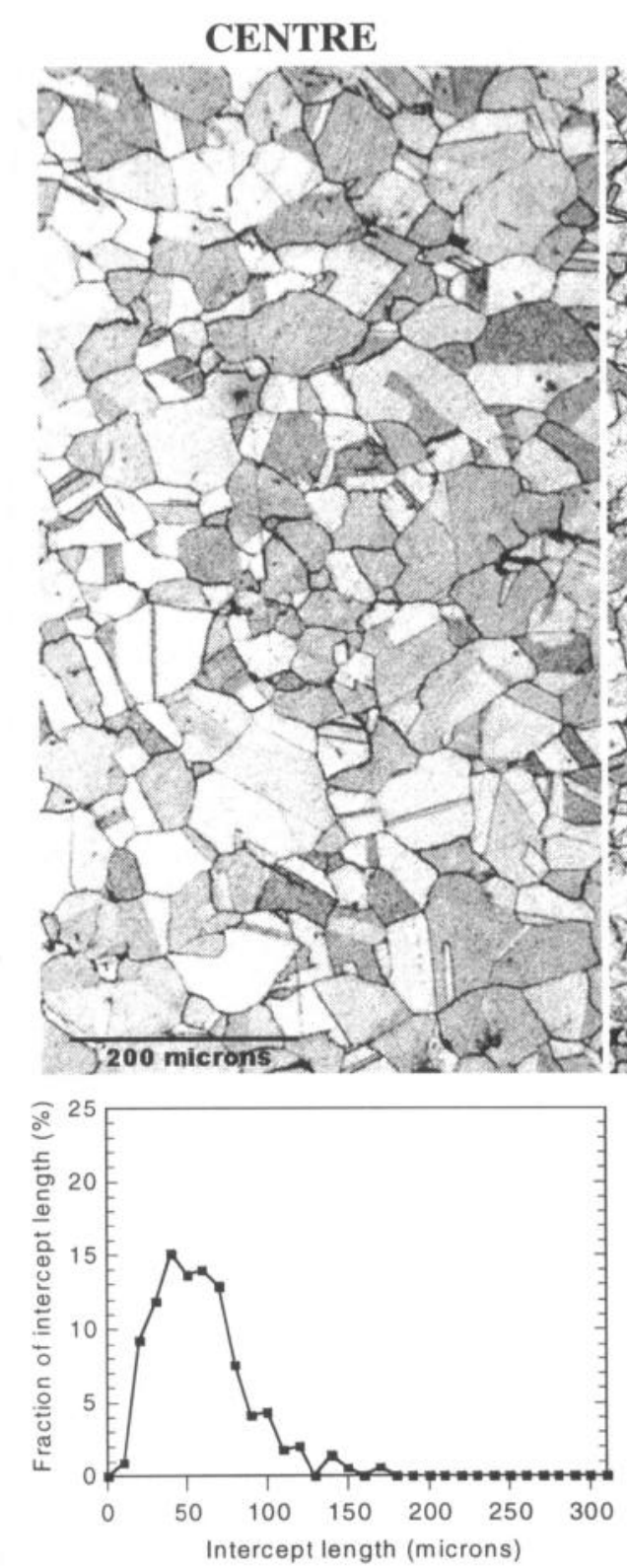

\section{MID-RADIUS}

PERIPHERY
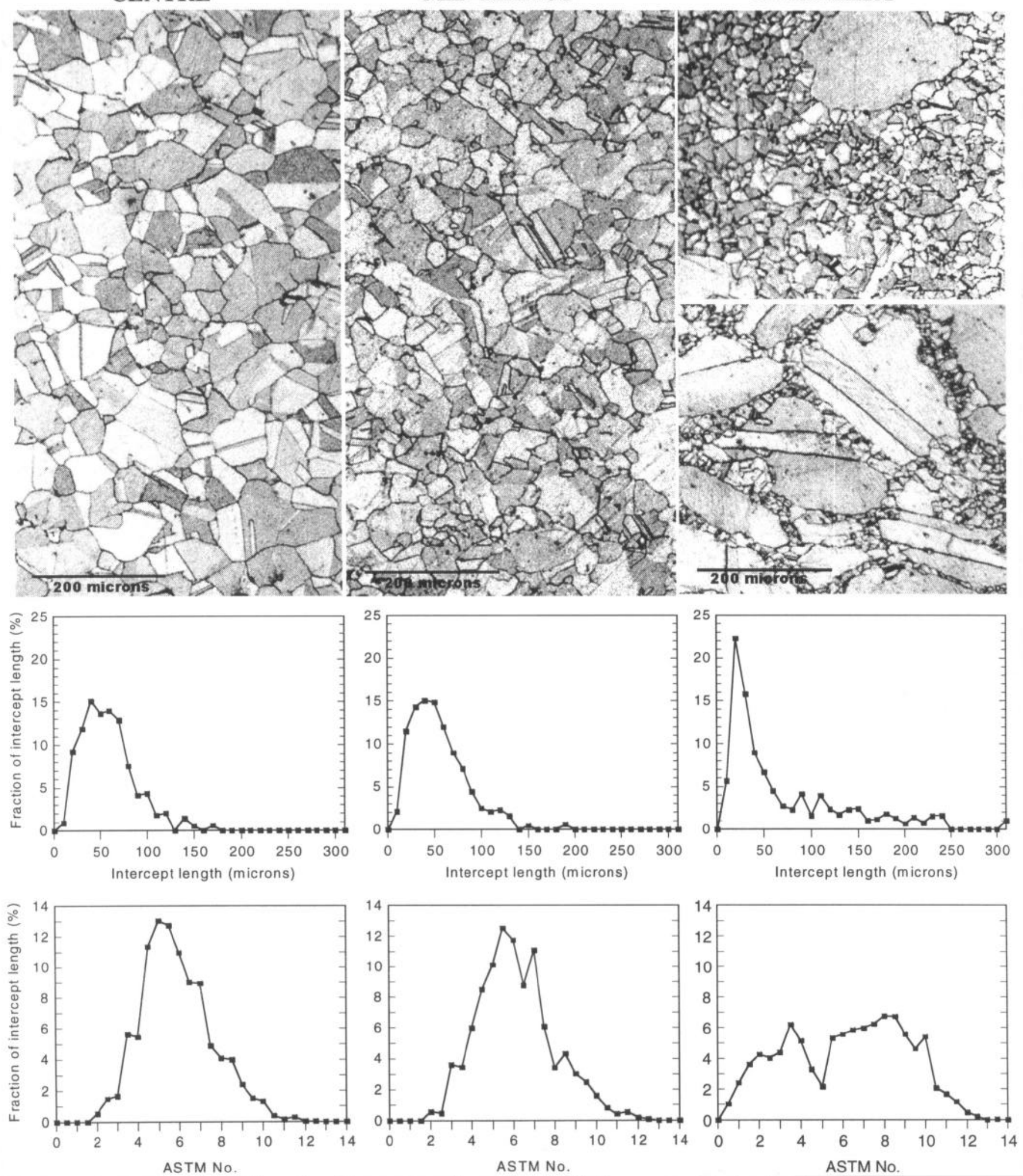

Figure 6. Micrographs and grain size distributions, measured using the linear intercept technique, from the centre, mid-radius and periphery of the final stage Waspaloy cogged billet. At the periphery two different microstructures were observed; micrographs of each are shown. 

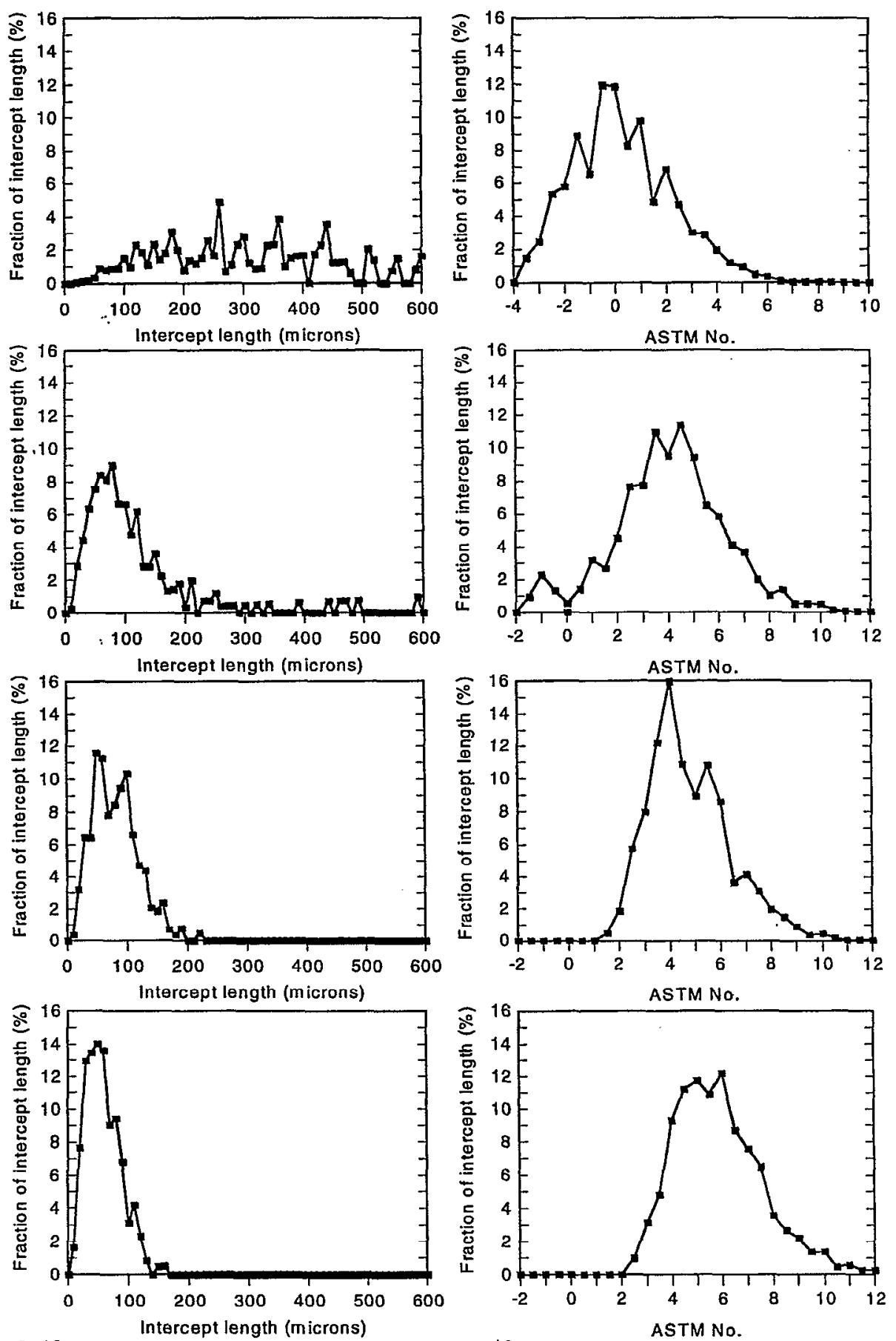

Figure 7.

Analysis of microstructure evolution at the centre of a Waspaloy ingot, during ingot-tobillet conversion. Grain size distributions were measured using the linear intercept technique, and taken for stages 3 to 7 (top to bottom respectively).
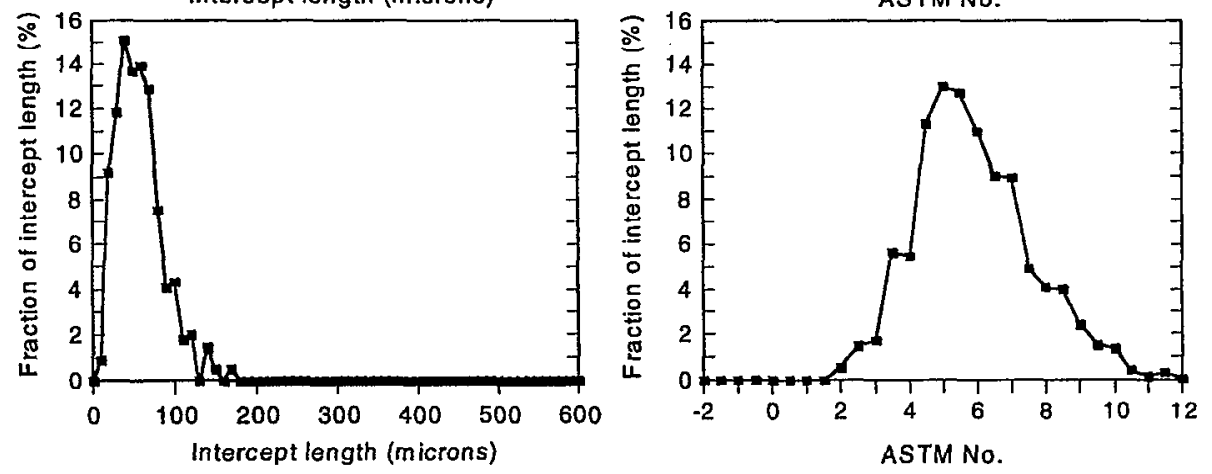
It can be seen from Figure 6 that a fairly uniform microstructure is achieved in both the centre and mid-radius locations of the billet material analysed. The slightly coarser nature of the centre material is due to the higher temperature associated with adiabatic heating, as demonstrated in the Inconel ${ }^{\circledR} 718$ model (Figures 2 and 5). The periphery shows a mixed microstructure of two forms. The upper micrograph shows a true mixed mode, partially recrystallised structure, and is a result of insufficient strain accumulation to fully recrystallise this zone. The structure in the lower micrograph exhibits the classical necklace appearance as described in the previous section.

Of some concern would be the small percentage of grains with an ASTM of 1 or 2 . Such grains are often associated with 'dead zones' in which the rate and amount of applied strain are insufficient to induce DRX. Figure 7 illustrates the steady improvement in microstructure brought about by the cogging procedure. The results represent the gradual refinement of the central ingot structure from ASTM 0 (stage 3) to ASTM 6 (stage 7).

\section{Dead zone evaluation}

One of the major objectives of process modelling is to enable the factory floor metallurgist to optimise actual forging schedules to refine the evolving microstructure. The underlying philosophy of this research considers that static grain growth is the dominant phenomenon governing microstructural development during ingot breakdown. A fundamental requirement for microstructural refinement, therefore, is the restriction of static grain growth. One may interrupt grain growth by ensuring DRX occurs during applied deformation.

The effect of variations in the process control parameters on the microstructure achieved is now examined, using the model as a predictive tool. Two parameters have been investigated, bite size and die speed. Process schedules combining slow die velocities with large bite sizes are compared to schedules combining fast die speeds with small bite sizes. We have found that the current combination of die speed and bite is near optimal. Small bites lack sufficient strain penetration at the billet centre thereby suppressing recrystallisation. Larger bites provide the necessary strain penetration to achieve full recrystallisation, however this is countered by excessive static grain growth times, and hence coarse microstructures, promoted by the slower die velocity. This is compounded by both the adiabatic heating in the centre which adds a further driver to the grain coarsening and excessive contact and radiative cooling to the periphery, resulting in a partially recrystallised grain structure. A small degree of process optimisation may be achieved through increases to both bite size and die velocity. This results in a more uniform microstructure with small levels of grain refinement achievable. In reality, such conditions may not be attainable since the hydraulic press is operated at near loading capacity.

The influence of squeezing the rounded sections of the octagonal section workpiece as opposed to the traditional approach of squeezing the flats has also been investigated. Figure 8(a) shows a macroetched section of Waspaloy billet, highlighting the areas of unrecrystallised material that are associated with the 'dead zones' created by forging on the flats. These dead zones are akin

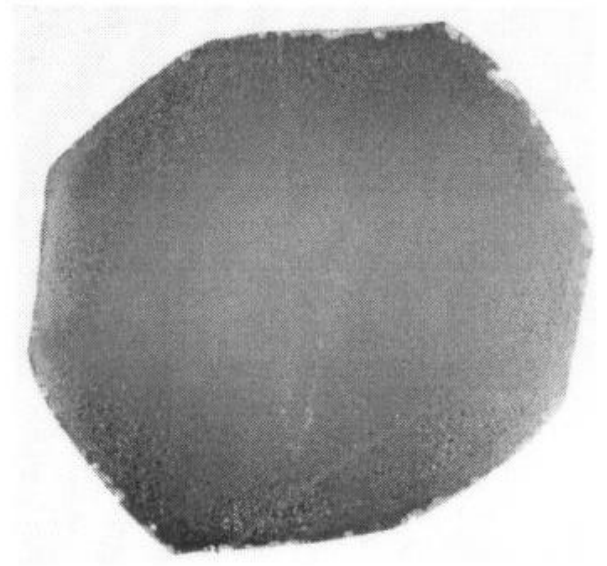

Figure 8(a). Macroetched billet section showing coarse microstructure in dead zones.

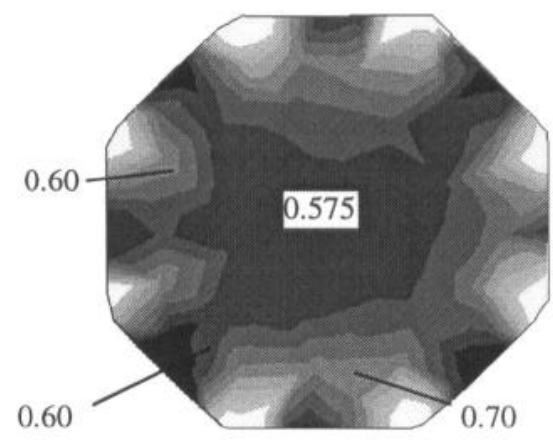

Figure $8(\mathrm{~b})$. Effective strain profile associated with squeezing flats.

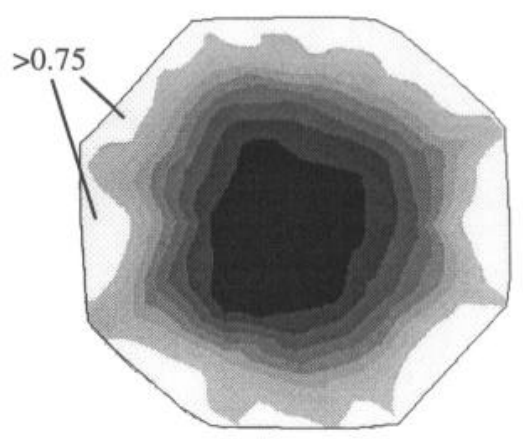

Figure 8(c). Effective strain profile associated with squeezing rounds. 
to those seen in lubricant free compression tests. Surface friction effects at the die/workpiece interface are sufficient to prevent a significant volume of the material from deforming. The restrained matcrial resides immediately under the die surface and exhibits a V-shape appearance. Figure 8(b) shows a typical effective plastic strain contour map taken from a two-stage process schedule simulation for Inconel ${ }^{\oplus} 718$. The first stage comprises four passes along one half of the ingot length to produce an octagonal crosssection. The workpiece is then rotated through $45^{\circ}$ to ensure that the next four passes deliver blows to the flats of the workpiece.

An alternative simulation was performed to investigate the effect of squeezing octagonal section corners. This process schedule was identical to the previous model in all respects other than the rotation at the end of pass four. Here the workpiece was rotated through $22.5^{\circ}$ thereby ensuring the delivery of subsequent blows to the rounded sections of the workpiece. The effective plastic strain profile for this approach is shown after the eighth pass (Figure $8(\mathrm{c})$ ). It is clear that there is a significant rise in the level of strain accumulation around the periphery of the workpiece. This increase in strain is induced due to the wider section of material that must be worked in order to achieve the desired reduction. It is the authors' contention that such a methodology would eliminate the coarse 'dead zone' regions as seen in the macroetched section (Figure 8(a)). A possible disadvantage to this approach is the lower level of strain penetration attained at the centre of the ingot. However, given the microstructural analysis carried out in Figure 7, it is likely that there would still be sufficient strain penetration in the course of the whole cogging process to ensure full recrystallisation. In fact this slight reduction in the level of strain experienced at the centre of the ingot might prove beneficial, with its associated reduction in adiabatic heating and thus a lowering of the driving force for static grain growth.

\section{Summary and Conclusions}

A computer-based process model has been presented to simulate microstructural evolution of nickel-base superalloys during ingotto-billct conversion. The theoretical approach has been validated by comparison to sectioned material taken from various stages in the cogging process. Analysis of macro-etched sections of the Waspaloy, indicate significant grain refinement through the cogging process, typically ASTM 0 to ASTM 6 at the center of the ingot. The microstructural analysis of the final stage Waspaloy material suggests that the bulk of the section is fairly uniform with only a slight variation in grain size from centre to mid-radius, the latter being slightly finer. This slight variation is attributed to the coarsening effect of the adiabatic heating at the centre of the ingot. Investigation of the periphery indicates two forms of partially recrystallised structure.

The microstructural model has been demonstrated to be effective in predicting the microstructures observed. A coarser recrystallised grain structure is predicted at the centre of the ingot, where a degree of adiabatic heating is modelled. Surface cooling effects due to radiation and die/billet interaction are also modelled successfully. From macroetched sections taken from an interrupted cogging schedule the effect of biting on the flats of a previous octagonal section are apparent. Such biting leads to a dead zone forming immediately below the die/ingot interface and extending someway into the cross section. Regions of unrecrystallised grains may be observed due to this lack of strain penetration. The process model accurately reflects these 'dead zones' and was then used to derive a new schedule where the level of strain penetration was more uniform around the periphery of the ingot.

\section{Acknowledgements}

The authors are grateful to the sponsors of this work, Rolls-Royce and notably Special Metals Wiggin Ltd. for the supply of material and processing details. In particular useful discussions with Specials employees, past and present; Richard Siddall, Dave 'Rocky' Rochard, Dave Lambert, Andy McGilvray, Gern Mauer, Bruce Antolovich and Lesh Patel are acknowledged. Thanks also to George Durrant at Rolls-Royce for his continued enthusiasm for this work and to Jeff Brooks and Mike Henderson at DERA for their advice. Chris Dandre was, and Carrie Walsh is, employed on an EPSRC/DERA funded joint grant scheme. (GR/L 66397, 'Microstructural Evolution in Ni-base Superalloys Forgings: Process Modelling and Validation').

\section{$\underline{\text { References }}$}

1) R.W. Evans, "Microstructural Modelling of Near Net Shape Forgings", (Paper presented at the EUROMAT'89 Conference, Aachen, FRG, 22-24 November 1989).

2) R.W. Evans, "Modelling of the Hot-Working of High Performance Alloys", Key Engineering Materials, 1993, 77. $78,227-240$.

3) R.A. Jaramillo et al. "Evaluation of an Inconel" Alloy 718 Microstructural Evolution Model", Superalloys 718, 625, 706 and Various Derivatives, (ed. E.A. Loria, Warrendale, TMS, 1997), 257-266

4) C.A. Dandre et al., "A Model Describing Microstructural Evolution for Nickel-Base Superalloy Forgings During the Cogging Process", Le Journal de Physique IV, v9, (1999), pp33-42.

5) D. Zhao et al., "Three dimensional simulation of Alloy 718 Ingot breakdown by Cogging", Superalloys 718, 625, 706 and Various Derivatives, (ed. E.A. Loria, Warrendale, TMS, 1997), 163-172.

6) C. Boyko, H. Henein, and F. Robert Dax, "Modelling of Open Die and Radial Forging Processes for Alloy 718", Superalloys 718,625 and Various Derivatives, (ed. E.A. Loria, Warrendale, TMS, 1991), 107-124.

7) J.P. Domblesky et al, "Prediction of Grain Size During Multiple Pass Radial Forging of Alloy 718", Superalloys $718,625,706$ and Various Derivatives, (ed. E.A. Loria, Warrendale, TMS, 1994), 263-272.

8) C.T.Sims, N.S. Stoloff, and W.C. Hagel, Superalloys II, (New York, NY:Wiley, 1987)

9) M. Durand-Charre, The Microstructure of Superalloys, (Gordon and Breach Science Publishers, 1997).

10) J.M. Zhang, Z.Y.Gou, J.Y. Zhuang, Z.Y. Zhong, 'Mathematical Modelling of the Hot Deformation Bchaviour of Superalloy IN718', Met \& Mat Trans A, (1999), 27012712

11) A.A. Guimaraes and J.J. Jonas, 'Recrystallisation and ageing effects associated with the high temperature deformation of Waspaloy and Inconel 718', Met. Trans. A (1981), 16551666.

12) R. Siddall private communications with authors, Special Metals Wiggin Ltd., Hereford, UK, February 2000. 
13) C.M. Sellars and W.J. McG. Tegart, "Hot Workability", International Metallurgical Reviews., (1972), 17, 1-24.

14) C.A. Dandre et al., "Microstructural evolution of Inconel 718 during ingot breakdown: process modelling and validation", Mat Sci \& Tech. v.16, (2000), 14-25

15) C.A. Dandre et al., "Exploring the Microstructural Evolution of Inconel 718 During Ingot Breakdown: Optimising the Cogging Process", (proceedings of COMPASS'99, University of Wales, Swansea, 1999).

16) M.C. Mataya and D.K. Matlock, "Effects of Multiple Reductions on Grain Refinement During Hot Working of Alloy 718", Superalloy 718 - Metallurgy and Application, (ed. E.A. Loria, Warrendale, TMS, 1989), 155-178.

17) M.C. Mataya, E.R. Nilsson and G. Krauss, "Comparison of Single and Multipass Compression Tests Used to Simulate Microstructural Evolution During Hot Working of Alloys 718 and 304L", Superalloys 718, 625, 706 and Various Derivatives, (ed. E.A. Loria, Warrendale, TMS, 1994), 331343.

18) D. Zhao, S. Guillard and A.T. Male, "High Temperature Deformation Behaviour of Cast Alloy 718", Superalloys 718, 625, 706 and Various Derivatives, (ed. E.A. Loria, Warrendale, TMS, 1997), 193-204.

19) M.J. Weiss et al., "The Hot Deformation Behaviour of an AsCast Alloy 718 Ingot”, Superalloy 718 - Metallurgy and
Application, (ed. E.A. Loria, Warrendale, TMS, 1989), 135154.

20) N. Srinivasan and Y.V.R.K. Prasad, "Microstructural Control in Hot Working of IN-718 Superalloy Using Processing Map", Met. \& Mat. Trans. A, 25A, (1994) 2275-2284.

21) W. Blum, and H.J. McQueen, "Dynamics of Recovery and Recrystallisation", Materials Science Forum, vols217-222, (1996), 31-42.

22) Annual book of ASTM Standards, v.03.01, E112, p227, 1996

\section{Nomenclature}

$\sigma \quad$ - flow stress

$\varepsilon_{2} \quad$ - strain at maximum stress

$\dot{\varepsilon} \quad$ - strain-rate

DRX - dynamic recrystallisation

$Q_{\text {def }} \quad$ - activation energy for deformation

$Q_{\varepsilon} \quad$ - activation energy for $\varepsilon_{2}$

$R \quad$ - gas constant

$\mathrm{T}$ - temperature

RXD - recrystallised

RXN - recrystallisation

SRX - static recrystallisation

$\alpha, A, n^{\prime}, B, m$ - material constants 